\title{
Psychosocial Disturbance of Hemodialysis Patients with Chronic Hepatitis B and C Virus Infection at Southern Provinces in Iraq
}

\author{
Qasim Ali Khasal ${ }^{1}$, Doaa Sami Rashash ${ }^{2}$, Fatima J. Shinjar ${ }^{3}$, Abdulrahman Abbas Jasim ${ }^{4}$ \\ ${ }^{1}$ Lecturer, Adult Nursing Department, College of Nursing/University of Thiqar/Iraq, ${ }^{2}$ Assistant Lecturer, Maternal \\ and Neonatal Health Nursing Department, College of Nursing/University of Thiqar/Iraq, ${ }^{3}$ Assistant Lecturer, \\ Adult Nursing Department, College of Nursing/University of Thiqar/Iraq, ${ }^{4}$ Assistant Lecturer, Thi-qar Health \\ Directorate/Department of training and human development
}

\begin{abstract}
Psychosocial issues are an understudied yet important concern in the overall health of hemodialysis (HD) patients. Stress is a concomitant of chronic illness and its treatment, and may have meaningful influences on psychological and medical outcomes.

A descriptive study was carried out to determine Psychosocial Disturbance among hemodialysis patients with chronic hepatitis virus infection. A non-probability of (60) hemodialysis patients with chronic hepatitis $\mathrm{B}$ and $\mathrm{C}$ virus. Reliability of the questionnaire form was determined through a pilot study while the content validity of the questionnaire was determined through a panel of experts. And then the Data were collected through the use of the observational tool (questionnaire), which was analyzed through the use of three statistical approaches. They are descriptive statistical analysis (frequencies, percentage, S.D, range of scores, mean of scores and relative sufficiency; inferential statistical analysis (correlation coefficient and chi- square test); and analysis of variance (ANOVA) . The study indicates that the Psychosocial domain has the effect due to hemodialysis with chronic viral hepatitis . The study indicated that the negative correlation between the socio-demographic and Psychosocial, except income, socioeconomic status at the social is relations/ support domain. On the basis of the results of the study, the researcher recommends to sharing the health cover given and family members to provide psychological support for hemodialysis patients with chronic viral hepatitis accept their condition that maintain peaceful live.
\end{abstract}

Keywords: Psychosocial, Hemodialysis Patients, Patients, Chronic Hepatitis.

\section{Introduction}

Hemodialysis patients have lower immune responses and are at a higher risk for infections viral hepatitis continues to be a potential serious ailment among hemodialysis patients both chronic hepatitis B

\footnotetext{
Corresponding Author:

Qasim Ali Khasal

Lecturer, Adult Nursing Department, College of

Nursing/University of Thiqar/Iraq

e-mail: qasem9361@gmail.com
}

and $\mathrm{C}$ have been implicated to be the main causes of viral hepatitis among hemodialysis patients ${ }^{1}$.Hemodialysis patients experience various problems that may adversely influence their quality of life. Hepatitis infection is also the most important problem in hemodialysis patients is that can affect their quality of life ${ }^{2}$. This long survival with hepatitis leads to Disturbance of psychosocial patient even in the absence of clinically significant renal disease; in particular the impact of hepatitis seems to be most dramatic in social and physical function, general health and vitality, such as the effects of hepatitis on families, work environments, and on society as a whole ${ }^{3}$. Chronic hepatitis are often thought of as of the most severe types of injuries resulting in dramatic 
change in all aspects of the individuals' life and having significant impact on their family and friends ${ }^{4}$. Also the loss of control over the body functions and altered life style secondary be caused by hepatitis, as evidenced by verbalization of inability to cope, expression of anger or other negative feelings ${ }^{5}$. Chronic diseases are associated with several psychosocial problems including quality of life, depression, anxiety and other psychological disorders. ${ }^{6}$ The measurement of psychosocial for patient is concerned with quantifying the judgments people make to describe their experiences of health and illness 5 .

\section{Material and Method}

Design of the Study: A descriptive quantitative design was carried out through the present study in order to achieve the early stated objectives during the period from 8th of January, 2019 to the 5th of July, 2019.

Setting of the Study: The study has been conducted on the hemodialysis patients with chronic viral hepatitis $\mathrm{B}$ and $\mathrm{C}$ at AL-Basra/AL-Basra Health Directorate/ AL-Basra Teaching Hospital/Hemodialysis Unit, ThiQar/Thi-Qar Health Directorate/AL- Hussein Teaching Hospital/Hemodialysis Unit,Misan/Misan Health Directorate/AL- Sader Teaching Hospital/Hemodialysis Units, Al-Muthanah/Al-Muthanah Health Directorate/ AL- Hussein Teaching Hospital/Hemodialysis Unit.

The Sample of the Study : A non-probability (purposive sample) of (60) hemodialysis patients with chronic hepatitis $\mathrm{B}$ and $\mathrm{C}$ virus.

The Study Instruments :for the purpose of the present study, a questionnaire was constructed by the researcher to study the variable for assessment Psychosocial Disturbance of Hemodialysis Patients with Chronic Hepatitis. The questionnaire was constructed thorough reviewing of previous literature and related studies for Psychosocial Disturbance of Hemodialysis Patients with Chronic Hepatitis . The study instrument comprised of (3) parts these parts related to the following:

Psychological: Domain This domain was measured through (5) sub-domains of negative feelings (7) items; self-esteem (4) items; thinking (5) items; memory and concentration (4) items; and appearance and body image (3) items.

Conducting Pilot Study: A convenient sample of (10) patients were selected from the inpatients in studied hospitals for hemodialysis patients are diagnosed by chronic viral hepatitis B and C this preliminary study was conducted for the period of December 10th, 2018 until the December 20th 2018

Determine the reliability of the questionnaire .Estimate the time required for the data collection .Obtain the clarity and the content adequacy of the questionnaire and observation Identify the barriers that may be encountered during the data collection process.

Validity: The validity of the instrument was established through a panel of (12) experts. who had more than five years' experience in their fields in order to achieve study objectives.

Reliability: results of the reliability showed very high level of stability and internal consistency of principle parts concerning item's responses' of the questionnaire, all those were calculated by using the major statistical parameter: Alpha Cronbach, revealed that the person correlation coefficient is $(0.73)$.

Statistical Analysis: The data analyzed through the application of statistical procedures and using the package of SPSS version (22).

\section{Results}

Table (1): Summary Statistics and Initial Assessment for Psychological Domain Towards patients According to Cutoff Point

\begin{tabular}{|l|c|c|c|c|c|}
\hline Items of the studied questionnaire & No. & Mean & Std. Dev. & R.S. \% & Ass. \\
\hline ((The Psychological Domain)) \\
\hline How did you feel \\
\hline Secluded from the rest of the people & 60 & 1.83 & 0.78 & 61.0 & Failure \\
\hline Upset because someone Anted & 60 & 1.63 & 0.76 & 54.3 & Failure \\
\hline Feel sad & 60 & 1.67 & 0.57 & 55.7 & Failure \\
\hline
\end{tabular}




\begin{tabular}{|c|c|c|c|c|c|}
\hline Items of the studied questionnaire & No. & Mean & Std. Dev. & R.S. \% & Ass. \\
\hline You feel uptight & 60 & 1.65 & 0.58 & 55.0 & Failure \\
\hline Quiet and peaceful & 60 & 1.63 & 0.61 & 54.3 & Pass \\
\hline Dismal and crisis & 60 & 1.68 & 0.57 & 56.0 & Failure \\
\hline Did you feel anxiety & 60 & 1.73 & 0.66 & 57.7 & Failure \\
\hline \multicolumn{6}{|l|}{ Self-Esteem } \\
\hline Did you suffer from the loss of real value, among others & 60 & 2.00 & 0.55 & 66.7 & Pass \\
\hline Did you feel the burden on others & 60 & 1.58 & 0.65 & 52.7 & Failure \\
\hline Did you feel the difference on people due to illness & 60 & 1.82 & 0.57 & 60.7 & Failure \\
\hline Did you feel compassion and pity of others toward you & 60 & 1.63 & 0.49 & 54.3 & Failure \\
\hline \multicolumn{6}{|l|}{ Thinking } \\
\hline Suffer from thinking about the future of your health & 60 & 1.38 & 0.61 & 46.0 & Failure \\
\hline Did you thinking about the cost of treatment & 60 & 1.48 & 0.60 & 49.3 & Failure \\
\hline Suffer from thinking about the future of your family & 60 & 1.48 & 0.65 & 49.3 & Failure \\
\hline Considering the length of the treatment period & 60 & 1.38 & 0.61 & 46.0 & Failure \\
\hline \multicolumn{6}{|l|}{ Memory and Concentration } \\
\hline Suffers from an inability to focus & 60 & 1.97 & 0.71 & 65.7 & Failure \\
\hline Suffer from cluttered thinking & 60 & 1.98 & 0.65 & 66.0 & Failure \\
\hline Experiencing difficulty understanding and learning & 60 & 1.98 & 0.65 & 66.0 & Failure \\
\hline Suffers from oblivion & 60 & 1.60 & 0.81 & 53.3 & Failure \\
\hline \multicolumn{6}{|l|}{ Body and Appearance } \\
\hline Feel that your body is different from others & 60 & 2.12 & 0.67 & 70.7 & Pass \\
\hline Feel that your appearance cause you shame & 60 & 2.17 & 0.67 & 72.3 & Pass \\
\hline Adhere to wear quality clothing & 60 & 2.33 & 0.71 & 77.7 & Pass \\
\hline
\end{tabular}

Mean of score (MS), standard deviation (SD), relative sufficiency (RS), Assessment (Ass).

This table (1) reveals the subjects responses of psychological domain in light of items of the sub domain named (how did you feel), shows failure assessment, since their relative sufficiency were under cutoff point, and they are accounted (61.0, 54.3, 55.7, 55.0, 54.3, 56.0, and 57.7) of the items (secluded from the rest of the people, upset because someone wanted, feel sad, you feel uptight, quiet and peaceful, dismal and crisis, and feel anxiety) respectively, then followed by sub domain named self-esteem, we can see that one subject's responses had pass assessment, named (did you suffer from the loss of real value, among others) with critical pass assessment due to relative sufficiency $(66.7 \%)$, while the leftover were reported failure assessment, and they are (did you feel the burden on others, did you feel the difference on people due to illness, did you feel compassion and pity of others toward you) and they are accounted $(52.7,60.7,60.7,54.3)$ respectively, then followed by sub domain named thinking, we can see that all subject's responses had failure assessment, named, and they are (suffer from thinking about the future of health, thinking about the cost of treatment, suffer from thinking about the future of family, and considering the length of the treatment period) and they are accounted (46.0, 49.3, 49.3, and 46.0) respectively, then followed by sub domain named memory and concentration, we can see that all subject's responses had Failure assessment, named, (suffers from an inability to focus, suffer from cluttered thinking, experiencing difficulty understanding and learning, and Suffers from oblivion) and they are accounted $(65.7,66.0,66.0$, and 53.3), then finally followed by sub domain named body and appearance, we can see that all subject's responses had pass assessment, since their relative sufficiency were upper cutoff point and they are (feel that body is different from others, feel that appearance cause shame, and adhere to wear quality clothing) and they are accounted (70.7, 72.3, and 77.7). 
Table (2): Summary Statistics and Initial Assessment for Social relations/support Domain Towards patients According to Cutoff Point.

\begin{tabular}{|c|c|c|c|c|c|}
\hline Items of the studied questionnaire & No. & Mean & Std. Dev. & R.S. \% & Ass. \\
\hline \multicolumn{6}{|l|}{$(($ Social relations/support Domain $))$} \\
\hline \multicolumn{6}{|l|}{ Social Relations } \\
\hline Convinced family relations & 60 & 1.42 & 0.62 & 47.3 & Pass \\
\hline Persuaded relations with the people & 60 & 1.73 & 0.76 & 57.7 & Pass \\
\hline Convinced harmony with people & 60 & 1.75 & 0.77 & 58.3 & Pass \\
\hline Convinced your social life and your relationships & 60 & 1.73 & 0.69 & 57.7 & Pass \\
\hline \multicolumn{6}{|l|}{ Material Support } \\
\hline Convinced owned funds & 60 & 2.27 & 0.58 & 75.7 & Pass \\
\hline Convinced control on your own money & 60 & 2.02 & 0.50 & 67.3 & Pass \\
\hline Important money for you & 60 & 1.65 & 0.52 & 55.0 & Failure \\
\hline Prevents the lack of money to do what you want & 60 & 1.93 & 0.45 & 64.3 & Failure \\
\hline
\end{tabular}

Mean of score (MS), standard deviation (SD), relative sufficiency (RS), Assessment (Ass).

This table (2)shows the subjects responses of social relations/support domain in light of items of the sub domain named (social relations), shows pass assessment, since their relative sufficiency were under cutoff point and they had negative direction of the ascending ordinal scale for the liker score regarding their items, and they are accounted (47.3, 57.7, 58.3, and 57.7) of the items (convinced family relations, persuaded relations with the people, convinced harmony with people, and convinced social life and relationships) respectively, then finally followed by sub domain named material support, we can see that all subject's responses had pass assessment, since their relative sufficiency were upper cutoff point and they are (convinced owned funds, and convinced control on your own money) and they are accounted (75.7, and 67.3), while the leftover items which were reported failure assessment, are (important money, and prevents the lack of money to do what you want) and they are accounted (55.0, and 64.3) respectively.

Table (3): Association Between Basis Information and Socio-Demographical Characteristics Variables with an Overall (QoL) Assessments due to Main Domains According to "Under/Upper" Cutoff point

\begin{tabular}{|c|c|c|c|c|}
\hline Main Domain & $\begin{array}{l}\text { Basis Information and Demographical } \\
\text { Characteristics X (QoL) Ass. Status }\end{array}$ & Contingency Coefficients & Approx. Sig. & C.S. $^{(*)}$ \\
\hline \multirow{10}{*}{$\begin{array}{l}\text { Psychological } \\
\text { domain }\end{array}$} & Hospital & 0.190 & $0 . .520$ & NS \\
\hline & Age Groups & 0.371 & 0.088 & NS \\
\hline & Gender & 0.155 & 0.225 & NS \\
\hline & Education Level & 0.297 & 0.324 & NS \\
\hline & Occupation & 0.248 & 0.415 & NS \\
\hline & Marital status & 0.266 & 0.205 & NS \\
\hline & Income & 0.171 & 0.406 & NS \\
\hline & Residency & 0.018 & 0.889 & NS \\
\hline & Crowding Index & 0.057 & 0.658 & NS \\
\hline & Socioeconomic Status & 0.239 & 0.163 & NS \\
\hline
\end{tabular}




\begin{tabular}{|l|l|c|c|c|}
\hline \multirow{2}{*}{ Main Domain } & $\begin{array}{l}\text { Basis Information and Demographical } \\
\text { Characteristics X (QoL) Ass. Status }\end{array}$ & Contingency Coefficients & Approx. Sig. & C.S. ${ }^{(*)}$ \\
\hline \multirow{5}{*}{$\begin{array}{l}\text { Social relations/ } \\
\text { support }\end{array}$} & Hospital & 0.258 & 0.234 \\
\cline { 2 - 5 } & Age Groups & 0.164 & 0.895 \\
\cline { 2 - 5 } & Gender & 0.219 & 0.083 \\
\hline & Education Level & 0.288 & 0.366 \\
\cline { 2 - 5 } & Occupation & 0.252 & 0.398 \\
\cline { 2 - 5 } & Marital status & 0.230 & 0.341 \\
\cline { 2 - 5 } & Income & 0.353 & 0.014 \\
\cline { 2 - 5 } & Residency & 0.047 & 0.717 \\
\cline { 2 - 5 } & Nrowding Index & 0.074 & NS \\
\cline { 2 - 5 } & Socioeconomic Status & 0.325 & NS \\
\hline
\end{tabular}

(*) NS : Non Sig. at $\mathrm{P}>0.05 ; \mathrm{S}$ : Sig. at $\mathrm{P}<0.05$

To predicting/or to find out the relationship between quality of life (QoL) domains and socio-demographic characteristics variables, correlation ship through the contingency coefficient of the contingency tables had been constructed in table (3) which were illustrated and testing the effectiveness distribution among different levels of the predicted variables and the two categories of an overall responding of assessment which were reported (under/upper) cutoff point at score value (2) for the Global Mean of Score.

The results has reported that the Socio-demographic characteristics variables (hospital, age groups, gender, education level, occupation, marital status income, residency, crowding index, and socioeconomic status) had no relationship with their overall (QoL) assessments due to main domains according to "Under/Upper" cutoff point for the grand mean of score values at each of the studied main domains, since a non-significant correlation ships were obtained at $\mathrm{P}>0.05$ except with gender factor at the physical status domain, and income, socioeconomic status at the social relations/ support domain, and we could conclude that the studied quality of life (QoL) questionnaire can be amend for all individual's population of "Hemodialysis Patients with Chronic Hepatitis B and C Virus Infection at Southern Provinces in Iraq" whatever a differences with their (Socio-demographic characteristics variables) would be. Relative to the table (1) the majority of the study sample individuals 48(80\%) are accounted at Al-Basra Hospital and the remaining are distributed at the others hospitals. This result also comes in agreement with Jawad et, al., 7 who stated of HCV antibody majority of the study sample(41\%) among HD patients in the Al-kadymia Teaching Hospital and the remaining are distributed at the others hospitals in hemodialysis unit.

\section{Conclusions}

A highest percent of the study sample were females more than males, they were illiterate, read and write, and primary school and married. They were unemployed, with good assessment crowding index, having low monthly income,mostly common occurs among patients in urban residential area more than in rural, with many complications involves all the body systems. The study indicates that the Psychosocial domain has the effect due to hemodialysis with chronic viral hepatitis. The study indicated that the negative correlation between the socio-demographic and Psychosocial, except income, socioeconomic status at the social is relations/support domain.

Financial Disclosure: There is no financial disclosure.

Conflict of Interest: None to declare.

Ethical Clearance: All experimental protocols were approved under the College Of Nursing, Iraq and all experiments were carried out in accordance with approved guidelines.

\section{References}

1. Ma Nanette V, Bernal-Sundiang MD, Rose Marie Ho-Yu M D, Gerardo F Ibarra M D.2009;46 (1): 31-42. 
2. Souvik S, Zhen J, Donna M, Abdus S, Wahed J, $\mathrm{H}$ Hoofnagle : Fatigue before, during and after antiviral therapy of chronic hepatitis C: Results from the Virahep-C study, Journal of Hepatology 2012; 3 .

3. Allam Muhammad Abdel-Hafiz Rizqallah. Adequacy of Hemodialysis among End Stage Renal, June 2008;7 (2): 233-239 .

4. Awan Masood S, Waqas Muhammad, Ali Mumtaz, et.al, status of health related quality of life between HBV and HCV patients of Pakistan.2001; 2,5,6,10.

5. Ayman A Abdo, Hepatitis $\mathrm{C}$ and poor quality of life: is it the virus or the patient, Saudi journal of Gastroenterology; 2008; 14 (3): 109- 113.

6. Kraus MR, Schäfer A, Faller H, et al. Psychiatric symptoms in patients with chronic hepatitis $\mathrm{C}$ receiving interferon alfa-2b therapy. J. Clin Psychiatry. 2003;64(6):708-714.

7. Jawad F, Jasim, HA.: Evaluation of knowledge and practices for kidney transplantation recipients. Inc. Journal, 2011; 34: 124-129.

8. Niederau C, Fischer C, Kautz A. Socio- economical aspects, quality of life and state of knowledge in hepatitis B patients. Soci-economical aspects in hepatitis B.Z Gastroenterology journal, 2007; 45 : 355-368.

9. Devivo MJ, Fine PR.: Hemodialysis Patient: it>s a Short-Term Impact on Marital Status. Arch Physical Medicine Rehabilitation, 1985;66 (1): 501-504
10. AL-Qureshi H, K.M bile, R Jooma, J E Alam, HUR Afridi; prevalence of hepatitis B and $\mathrm{C}$ viral infection in Pakistan . Estern Mediterranean Health Journal (EMHJ) 2010; 16 supplement.

11. Adela paez J, Noha S El-din, Mostafa El-Hoseiny, Mai-El-daly, Mohammed Abdel-Hamid, S El-Aidi, et.al;community transmission of hepatitis B virus in Egypt: results from a case control study in Greater Cairo, international journal of epidemiology, 2009; 38: 757-765

12. Gogos CA, Fouka KP, G Nikiforidis, K Avgeridis, $\mathrm{G}$ Sakellaropoulos, $\mathrm{H}$ Bassaris A maniatis, A skoutelis, prevalence of hepatitis $\mathrm{B}$ and $\mathrm{C}$ virus infection in the general population and selected groups in south - western Greece, European journal of epidemiology; 2003; 18: 551- 557.

13. Misra B,Panda C,Das Hs, nayak Kc, Singh Sp., study on awareness about hepatitis B virus infection in costal Eastern India .hepatitis B annual,2009; 6:1228.

14. Nasser E, Mohammed B, Mehdi k Mohamed R, Narges E, Amir-Abbas S., prevalence of psychiatric disorders in hepatitis B virus carriers in Iranian charity for hepatitis patients support . hepatitis monthly Journal, 2008; 8 (3): 201-205.

15. Barkhuizen A, Rosen HR, Aolf S, Flora K., Bennett Rm. Musculoskeletal pain and fatigue are associated with chronic hepatitis C : Areport of 239 hepatology clinic patients. American Medical Journal Gastroenterology; 1999; 94: 1355-1360 